\title{
Implementing a systems-oriented morbidity and mortality conference in remote rural Nepal for quality improvement
}

\author{
Dan Schwarz, ${ }^{1,2,3}$ Ryan Schwarz, ${ }^{1,4,5}$ Bikash Gauchan, ${ }^{1}$ Jason Andrews, ${ }^{1,6}$ \\ Ranju Sharma, ${ }^{1}$ Gregory Karelas, ${ }^{1}$ Ruma Rajbhandari, ${ }^{1,4}$ Bibhav Acharya, ${ }^{1,7}$ \\ Kedar Mate, ${ }^{4,8,9}$ Amir Bista, ${ }^{1}$ Megha Giri Bista, ${ }^{1}$ Colin Sox, ${ }^{10}$ \\ Duncan Smith-Rohrberg Maru ${ }^{1,4,5,10}$
}

For numbered affiliations see end of article.

Correspondence to Dr Duncan Smith-Rohrberg Maru, 42 Union Ave., Boston, MA 02130, USA; duncansr@post.harvard.edu

Accepted 31 August 2011 Published Online First 26 September 2011

\section{UNLOCKA}

This paper is freely available online under the BMJ Journals unlocked scheme, see http://qualitysafety.bmj. com/site/about/unlocked. $\mathrm{xhtml}$

\section{ABSTRACT}

Problem: In hospitals in rural, resource-limited settings, there is an acute need for simple, practical strategies to improve healthcare quality.

Setting: A district hospital in remote western Nepal. Key measures for improvement: To provide a mechanism for systems-level reflection so that staff can identify targets for quality improvement in healthcare delivery.

Strategies for change: To develop a morbidity and mortality conference (M\&M) quality improvement initiative that aims to facilitate structured analysis of patient care and identify barriers to providing quality care, which can subsequently be improved.

Design: The authors designed an M\&M involving clinical and non-clinical staff in conducting root-cause analyses of healthcare delivery at their hospital. Weekly conferences focus on seven domains of causal analysis: operations, supply chain, equipment, personnel, outreach, societal, and structural. Each conference focuses on assessing the care provided, and identifying ways in which services can be improved in the future.

Effects of change: Staff reception of the M\&Ms was positive. In these M\&Ms, staff identified problem areas in healthcare delivery and steps for improvement. Subsequently, changes were made in hospital workflow, supply procurement, and on-site training. Lessons learnt: While widely practiced throughout the world, M\&Ms typically do not involve both clinical and non-clinical staff members and do not take a systems-level approach. The authors' experience suggests that the adapted M\&M conference is a simple, feasible tool for quality improvement in resource-limited settings. Senior managerial commitment is crucial to ensure successful implementation of M\&Ms, given the challenging logistics of implementing these programmes in resource-limited health facilities.

\section{THE PROBLEM}

Simple, effective tools are needed to improve quality in resource-limited health facilities (unpublished data, Maru et al. 2011). The morbidity and mortality conference (M\&M) is a well established practice globally. ${ }^{1-5}$ There is, however, limited experience with M\&M as a hospital-wide quality improvement strategy in resource-limited settings. While clinical and process audits have been piloted for conditions such as maternal or perinatal disease, ${ }^{6-8}$ to our knowledge there are no published reports of hospital-wide M\&Ms in resourcelimited settings. Furthermore, there is limited experience in utilising M\&Ms to encourage better understanding of systems-level healthcare issues, and to encourage transparent, non-punitive discussion among staff regarding areas for improvement. Some recent literature $^{49-12}$ has highlighted the importance of these aspects of M\&Ms, but they are not yet well implemented across resource-poor settings.

Given that M\&Ms are common throughout the world, a refocusing of the M\&M as a systems-level quality improvement intervention could be feasible in many resourcelimited settings. Here we present a qualitative observational study of the implementation of a hospital-wide M\&M as a quality improvement initiative at a district hospital in remote western Nepal.

\section{METHODS}

\section{Setting}

Achham is a remote district in western Nepal and is the third poorest district in one of the 
world's poorest countries. It has a primarily agrarian $(60 \%)$ population of 266000 . Median annual household income is US $\$ 141$ with literacy rates of $52 \%$ for men and $14 \%$ for women. Chronic malnutrition rates for children under five are $63.5 \%,{ }^{13}$ and maternal mortality rates are 231 per $100000 .^{14}$

Bayalpata Hospital (BH) opened in 2009 and is one of only two hospitals in Achham. BH is run by the nonprofit organisation Nyaya Health in partnership with the Nepali Ministry of Health and Population. In 2010, BH treated over 23000 outpatients and inpatients. BH has 28 Nepali staff, 23 (82\%) of whom are from Achham or neighbouring districts. Thirteen $(46 \%)$ are women, including two of the five (40\%) senior hospital management positions. Literacy rates are $92 \%$ for female staff and $93 \%$ for male staff, with $46 \%$ of female staff and $60 \%$ of male staff having post-secondary education. The clinical staff are overseen by the medical director (BG), who has received his medical bachelor's degree and has 1 year of postgraduate work experience. The clinical team also includes one medical officer (a bachelor's level physician), two senior nurses (with bachelor's degree training), two mid-level practitioners (3 years training post-secondary school), and five midwives (18 months training post-secondary school). In addition to these fulltime employees, there is one full-time Nepali Bayalpata Hospital volunteer director of community health (RS), and one full-time expatriate volunteer executive director (DS). Both volunteers played a significant role in developing and implementing the M\&M.

\section{Strategy for change}

Prior to this programme, $\mathrm{BH}$ lacked a mechanism for systems-level reflection enabling staff to identify challenges and areas for quality improvement in healthcare delivery. The authors hypothesised that a hospital-wide M\&M would be a feasible quality improvement initiative aimed to facilitate structured analysis and improvement of patient care. Successful change was defined as the implementation of this M\&M with staff-wide involvement and tangible changes seen in healthcare delivery at $\mathrm{BH}$.

\section{M\&M programme design}

In M\&Ms, BH staff review recent clinical cases using root cause analysis of M\&M, identifying systems failures and opportunities for future improvement. In order to address the inter-relatedness of quality challenges across both clinical and non-clinical departments, all hospital personnel are encouraged to participate in M\&Ms. To facilitate broad participation, M\&Ms are conducted during protected time at weekly staff meetings. Given the small staff size and limited clinical expertise at $\mathrm{BH}$, external volunteer physicians offer further clinical input via email. Approximately 15 clinicians participate, including Nepali physicians in Nepal and abroad, American physicians, and other colleagues of Nyaya Health.

The M\&M process begins with the weekly selection of a complicated clinical case by BH's medical director. Cases are selected with input from clinical staff, focusing on cases in which staff feel that the clinical management and/or the non-clinical aspects of management can be improved. Due to the volume of cases seen at $\mathrm{BH}$, not all cases can be reviewed, but as a policy, all mortalities are reviewed. After selecting the case, a case summary, including questions requiring guidance, is circulated to external volunteer physicians who offer feedback regarding clinical management prior to the M\&M. Preparation for each week's M\&M, including writing the case summary and communicating with external volunteer physicians, typically involves at least $2-3 \mathrm{~h}$ of work on behalf of the medical director. BH's hospital administrator and executive director are frequently involved in this preparation as well.

M\&Ms occur during weekly staff meetings, with a 30-60 min case discussion structured around seven domains of causal analysis relevant to the resourcelimited setting in which BH operates. Staff discussion is supplemented by input received from external volunteer physicians. The seven discussion domains were derived from the classic Ishikawa method: ${ }^{15}$

- Clinical operations - concerns with patient flow, intake, or processing in clinical departments, laboratory, radiology, or pharmaceutical operations.

- Supply chains-challenges in obtaining reliable supplies of quality medicines or equipment.

- Equipment-issues in the functioning, quality, or availability of equipment.

- Personnel-factors pertaining to training, professionalism, management, or collaboration.

- Outreach-issues in recruiting patients into timely and appropriate care through community engagement.

- Societal-challenges faced by gender, caste, economic, or other social status.

- Structural-factors related to infrastructure, such as roads, telecommunications, educational or healthcare facilities.

The medical director facilitates discussion and actively solicits contributions from all staff present. The M\&M concludes with a review of lessons learnt and recommendations, and responsible personnel and timelines are identified for implementation of recommendations. Afterwards, a case summary is circulated to external volunteer physicians for review, and final transcripts are made publicly accessible. ${ }^{16}$

After the M\&M conference, the medical director, hospital administrator, and executive director oversee the implementation of proposed changes to clinical or non-clinical operations. These duties vary by case, and 
due to their broad scope, can often take weeks or even months to fully implement. Other staff are often charged with these responsibilities, for example, the medical director oversees the midwives revising delivery protocols. All preparation and follow-up responsibilities are included in job descriptions; staff are not paid extra or provided separate time for these duties.

\section{Study methods}

We conducted a 9-month, qualitative observational study of the implementation of this M\&M programme. We obtained ethical review for this study from both the Nepal Health Research Council and Boston Medical Center's Institutional Review Board (USA).

M\&M discussions, quoting directly from staff members in real time, were transcribed and translated into English by one of the authors (RS). Throughout the study, formal programme reviews were conducted at 3-month intervals. These reviews were facilitated by the medical director and included all staff members. During these reviews, we elicited staff responses concerning M\&M participation, impact of M\&Ms on individual and collective work practices, impact of M\&Ms on hospital policies, value of input by external volunteer physicians, and barriers to implementation of M\&Ms.

A grounded theory approach was used for analysis, in which two authors (DS, RS) reviewed transcripts and coded content. The coding revealed two primary categories: the effect of M\&Ms on staff and the effect of M\&Ms on hospital operations. Further analysis of both categories demonstrated six primary themes within staff effects, and three primary themes within hospital operations effects. These themed analyses are described qualitatively below.

\section{EFFECTS OF CHANGE}

\section{Scope of M\&M cases}

Cases encompassed a wide breadth of clinical conditions. Summaries of cases, the problems identified, and the recommendations made are presented in table 1 , and an example case summary is given in box 1 .

\section{Participation and staff response}

Typically, $80-85 \%$ of on-duty personnel attended M\&Ms. Overall, M\&Ms were received positively by personnel, although the programme struggled with consistency and oversight. Staff members identified five key benefits to the M\&M; here we present select staff comments, excerpted from programme reviews and individual M\&M meeting notes:

- More rigorous case analysis and identification of areas for improvement: 'It's been 2 years since the hospital opened but until now we have never been able to analyse and think in depth about how the critical cases are managed' (nurse); 'It is not just a review of a particular case, but a review of our hospital: what the problems are, what is missing, and what can be done to improve' (staff physician).

- Improved collaboration and team-based learning: 'Cases are only managed by a few personnel and are not well understood by the rest of the staff, so these M\&Ms help us to learn from the lessons of the other staff in those cases' (laboratory assistant); 'Staff learn from each other, and when we think in retrospect critically about the cases...we learn the value of team efforts in regards to our shortcomings and how we can improve next time' (staff physician).

- Better understanding of clinical operations among non-clinical staff: 'We non-clinical staff gain an improved background of what kind of cases we see at the hospital and how the clinical operations function...this also helps us to explain what services Bayalpata Hospital offers to various community members who ask us about their health problems' (data manager); 'These discussions have helped me to learn things that are directly relevant to my work here at Bayalpata Hospital...for example, the various drugs that we use and how to order the different doses, which previously I did not understand and led to mistakes in purchasing' (accountant).

- Improved communication between junior and senior staff members: 'Clinical and administrative managers learn about the logistical problems of junior staff members that they might not know about otherwise' (medical director).

- External volunteer clinical consultations: 'With these outside physician volunteers, I am able to gain much information that was previously unknown to me about case management, and it is helpful to feel support from senior physicians even though we have such small staffing here' (staff physician).

\section{Challenges}

Despite these benefits, the programme has encountered challenges. Some non-clinical staff members have been frustrated by M\&Ms: '... they are helpful in some ways, but I don't think that all non-clinical staff should always have to attend because sometimes it's not helpful' (data manager). Additionally, staff have noted that 'it is frustrating to keep discussing the same issues, but they are not yet resolved. We know some things take long times, but the management should be faster and more effective about addressing these problems' (nurse). The latter concern has been particularly relevant for issues of long-term improvement, such as development of community health worker networks and improvement of water or electrical facilities.

The programme has also had difficulty with oversight and staffing. During the course of the study period, 
Table 1 Selected cases from Bayalpata Hospital's morbidity and mortality conference*

\begin{tabular}{|c|c|c|c|c|}
\hline Age, sex & $\begin{array}{l}\text { Primary } \\
\text { diagnosis }\end{array}$ & Problems identified & $\begin{array}{l}\text { Domains of Causal } \\
\text { Analysis }\end{array}$ & Recommendations \\
\hline \multirow[t]{2}{*}{$\begin{array}{l}20 \text { years, } \\
\text { woman }\end{array}$} & \multirow[t]{2}{*}{$\begin{array}{l}\text { Intrauterine } \\
\text { fetal } \\
\text { demise }\end{array}$} & $\begin{array}{l}\text { Laboratory staffing is } \\
\text { insufficient at times of high } \\
\text { patient volume }\end{array}$ & $\begin{array}{l}\text { Clinical operations, } \\
\text { Personnel }\end{array}$ & $\begin{array}{l}\text { Additional training for nurses and } \\
\text { mid-level practitioners should be } \\
\text { conducted by lab personnel to } \\
\text { enable lab task shifting during } \\
\text { times of high patient volume }\end{array}$ \\
\hline & & $\begin{array}{l}\text { There is a lack of trained } \\
\text { ultrasonographers at the } \\
\text { hospital }\end{array}$ & $\begin{array}{l}\text { Clinical operations, } \\
\text { Equipment, Personnel }\end{array}$ & $\begin{array}{l}\text { Management should investigate } \\
\text { options for off-site intensive } \\
\text { training for a staff member }\end{array}$ \\
\hline $\begin{array}{l}6 \text { years, boy, } \\
12 \text { years, boy }\end{array}$ & $\begin{array}{l}\text { Botulism } \\
\text { poisoning }\end{array}$ & $\begin{array}{l}\text { Clinicians are not in contact } \\
\text { with private pharmacies and } \\
\text { traditional healers in the } \\
\text { villages }\end{array}$ & $\begin{array}{l}\text { Clinical operations, } \\
\text { Personnel, } \\
\text { Outreach, Societal }\end{array}$ & $\begin{array}{l}\text { Management should develop } \\
\text { a list of contact information and } \\
\text { meetings should be set up at the } \\
\text { hospital and in the community for } \\
\text { relationship building }\end{array}$ \\
\hline \multirow[t]{2}{*}{28 years, man } & \multirow[t]{2}{*}{$\begin{array}{l}\text { Suicide } \\
\text { attempt }\end{array}$} & $\begin{array}{l}\text { There is a lack of mental } \\
\text { health services in our } \\
\text { catchment area }\end{array}$ & $\begin{array}{l}\text { Clinical operations, } \\
\text { Personnel, Structural }\end{array}$ & $\begin{array}{l}\text { Medical director and } \\
\text { management should develop } \\
\text { emergency referral list and crisis } \\
\text { line with psychiatrists in the } \\
\text { capital }\end{array}$ \\
\hline & & $\begin{array}{l}\text { Pharmacy lacks any type of } \\
\text { anti-depressant medications. }\end{array}$ & $\begin{array}{l}\text { Clinical operations, } \\
\text { Supply chains }\end{array}$ & $\begin{array}{l}\text { Management should procure at } \\
\text { least two different medicines and } \\
\text { identify long-term suppliers }\end{array}$ \\
\hline \multirow[t]{2}{*}{8 months, boy } & \multirow[t]{2}{*}{ Pneumonia } & $\begin{array}{l}\text { Oxygen tanks are unavailable } \\
\text { locally, and pre-existing tanks } \\
\text { cannot be refilled locally }\end{array}$ & $\begin{array}{l}\text { Clinical operations, } \\
\text { Equipment, } \\
\text { Supply chains, } \\
\text { Structural }\end{array}$ & $\begin{array}{l}\text { Management should procure } \\
\text { tanks and oxygen from the } \\
\text { capital for the ER, inpatient } \\
\text { wards, and the ambulance }\end{array}$ \\
\hline & & $\begin{array}{l}\text { AMBU bags are not easily } \\
\text { accessible in emergency } \\
\text { situations }\end{array}$ & $\begin{array}{l}\text { Clinical operations, } \\
\text { Equipment, } \\
\text { Personnel }\end{array}$ & $\begin{array}{l}\text { Senior nurse should identify } \\
\text { a designated location for bag } \\
\text { valve masks in the ER and } \\
\text { inpatient wards, spaced in close } \\
\text { proximity to all beds to avoid } \\
\text { delays in administering care }\end{array}$ \\
\hline \multirow[t]{2}{*}{19 years, woman } & \multirow[t]{2}{*}{$\begin{array}{l}\text { Retained } \\
\text { placenta }\end{array}$} & $\begin{array}{l}\text { Some mid-level practitioners } \\
\text { and nurses are unfamiliar with } \\
\text { basic resuscitation protocols }\end{array}$ & $\begin{array}{l}\text { Clinical operations, } \\
\text { Personnel }\end{array}$ & $\begin{array}{l}\text { On-site protocol review should be } \\
\text { conducted by the senior } \\
\text { physicians }\end{array}$ \\
\hline & & $\begin{array}{l}\text { Limited pharmacy staffing } \\
\text { leads to problems at times of } \\
\text { high patient volume }\end{array}$ & $\begin{array}{l}\text { Clinical operations, } \\
\text { Personnel }\end{array}$ & $\begin{array}{l}\text { The pharmacist should conduct } \\
\text { task-shifting workshops for } \\
\text { medicine dispensing and } \\
\text { stocking for nurses and mid-level } \\
\text { practitioners }\end{array}$ \\
\hline 35 years, woman & $\begin{array}{l}\text { Motor vehicle } \\
\text { accident }\end{array}$ & $\begin{array}{l}\text { ER ultrasounds are not being } \\
\text { administered in a timely } \\
\text { fashion }\end{array}$ & $\begin{array}{l}\text { Clinical operations, } \\
\text { Equipment, } \\
\text { Personnel }\end{array}$ & $\begin{array}{l}\text { ER ultrasound utilisation } \\
\text { protocols should be developed by } \\
\text { physicians to ensure that patients } \\
\text { receive urgent scans when } \\
\text { indicated }\end{array}$ \\
\hline \multirow[t]{2}{*}{87 years, man } & \multirow[t]{2}{*}{ COPD } & $\begin{array}{l}\text { Close observation of patients } \\
\text { with COPD has been } \\
\text { insufficient due to visibility } \\
\text { from the nurses' station }\end{array}$ & $\begin{array}{l}\text { Clinical operations, } \\
\text { Personnel }\end{array}$ & $\begin{array}{l}\text { Senior nurse should designate } \\
\text { a specific bed in the ER for these } \\
\text { patients with close observation } \\
\text { and all necessary equipment in } \\
\text { close proximity }\end{array}$ \\
\hline & & $\begin{array}{l}\text { The pharmacy lacks any } \\
\text { inhalers. }\end{array}$ & $\begin{array}{l}\text { Clinical operations, } \\
\text { Supply chains }\end{array}$ & $\begin{array}{l}\text { Management and the pharmacist } \\
\text { should procure multiple types of } \\
\text { inhalers for both inpatient and } \\
\text { outpatient management of } \\
\text { respiratory disease. }\end{array}$ \\
\hline
\end{tabular}




\begin{tabular}{|c|c|c|c|c|}
\hline Age, sex & $\begin{array}{l}\text { Primary } \\
\text { diagnosis }\end{array}$ & Problems identified & $\begin{array}{l}\text { Domains of Causal } \\
\text { Analysis }\end{array}$ & Recommendations \\
\hline \multirow[t]{2}{*}{60 years, man } & \multirow[t]{2}{*}{ Tuberculosis } & $\begin{array}{l}\text { Tuberculosis diagnostic } \\
\text { criteria are not being } \\
\text { appropriately followed }\end{array}$ & $\begin{array}{l}\text { Clinical operations, } \\
\text { Equipment, } \\
\text { Personnel }\end{array}$ & $\begin{array}{l}\text { Clinicians and lab personnel } \\
\text { should henceforth utilise both } \\
\text { radiological and sputum-based } \\
\text { diagnostic testing }\end{array}$ \\
\hline & & $\begin{array}{l}\text { Staff attend off-site training } \\
\text { but do not share their new } \\
\text { knowledge and skills with } \\
\text { other staff }\end{array}$ & $\begin{array}{l}\text { Clinical operations, } \\
\text { Personnel }\end{array}$ & $\begin{array}{l}\text { Management should institute } \\
\text { post-training skill-sharing } \\
\text { workshops for all staff members } \\
\text { attending training }\end{array}$ \\
\hline 17 years, man & Head trauma & $\begin{array}{l}\text { Patients in the ER wait for } \\
\text { long periods of time even for } \\
\text { simple items like intravenous } \\
\text { fluids }\end{array}$ & $\begin{array}{l}\text { Clinical operations, } \\
\text { Equipment, } \\
\text { Personnel }\end{array}$ & $\begin{array}{l}\text { The medical director and senior } \\
\text { nurse should institute standing } \\
\text { orders for ER patients }\end{array}$ \\
\hline \multirow[t]{2}{*}{$\begin{array}{l}36 \text { years, } \\
\text { woman }\end{array}$} & \multirow[t]{2}{*}{$\begin{array}{l}\text { Antepartum } \\
\text { haemorrhage }\end{array}$} & $\begin{array}{l}\text { Partographs are being used } \\
\text { inconsistently and improperly }\end{array}$ & $\begin{array}{l}\text { Clinical operations, } \\
\text { Equipment, } \\
\text { Personnel }\end{array}$ & $\begin{array}{l}\text { Physicians and senior nurse } \\
\text { should conduct partograph } \\
\text { training, along with beginning } \\
\text { a programme to monitor weekly } \\
\text { partograph completion rates and } \\
\text { the review of all completed } \\
\text { partographs }\end{array}$ \\
\hline & & $\begin{array}{l}\text { Patient family members } \\
\text { receive low-quality and } \\
\text { inconsistent counselling in } \\
\text { the ER }\end{array}$ & $\begin{array}{l}\text { Clinical operations, } \\
\text { Personnel, Societal }\end{array}$ & $\begin{array}{l}\text { The medical director and } \\
\text { management should identify } \\
\text { a key person to provide } \\
\text { counselling to ER patient family } \\
\text { member }\end{array}$ \\
\hline
\end{tabular}

*Many of these M\&Ms had several recommendations but for the purpose of this paper, we have simply provided a selection from each case. COPD, chronic obstructive pulmonary disease; ER, emergency room.

despite the weekly programme design, M\&Ms have only occurred in 19 of 35 weeks (54\%). Of the missed weeks, eight occurred between December 2010 and January 2011, a period during which the executive director was off site and other staff shortages were present coincidentally. Other M\&Ms that were missed were often a result of need to stop or postpone the meeting to handle emergency care during the staff meeting time.

Another challenge has been promoting active involvement of all staff. Despite efforts to create 'open dialogue', junior staff, who are often less well educated and/or from lower social castes, participate less than other staff. In M\&M transcript reviews, an average of only $8 \%$ of the comments were made by such staff members, despite them accounting for $46 \%$ of the staff. The same has been true with regards to gender dynamics, with women contributing an average of only $31 \%$ of the comments, despite accounting for $46 \%$ of the staff.

\section{Hospital operations}

In addition to benefits and challenges discussed by staff, M\&Ms have also led to changes in hospital operations. Some examples of these changes are given below.

\section{Workflow modifications}

An M\&M reviewing a complicated delivery highlighted the need for enhanced laboratory staffing during times of high patient volume (Domains of Causal Analysis: Clinical operations and Personnel). This resulted in laboratory personnel conducting task-shifting workshops for all clinical staff to conduct emergency, point-of-care investigations, such as blood chemistries, complete blood counts, HIV, and pregnancy tests. These sessions occurred 3 weeks after the M\&M, and since have enabled task shifting during periods of high patient flow, resulting in improved laboratory capacity.

\section{On-site clinical training}

An M\&M reviewing a complicated delivery found inconsistent and improper recording of partographs (Domains of Causal Analysis: Clinical operations, Equipment, and Personnel). On review of the previous 4 weeks of deliveries, a baseline partograph completion rate of only $20 \%$ was noted. This led to a teaching session by physicians targeted at nurse midwives on the importance of partographs during the active stage of labour. Simultaneously, clinicians started a monitoring programme which involved evaluating the percentage of partographs completed per week and reviewing each completed partograph. In the subsequent 2 months, partograph completion rates increased to $76 \%$, but not all forms were completed correctly. The programme remains in place, now focusing on correct utilisation of forms in addition to completion rates. 
Box 1 Example of morbidity and mortality (M\&M)

Case selection

An 8-month-old boy presents with severe pneumonia, proceeds through a complicated hospital course, and dies of cardiopulmonary arrest. The medical director identifies the case as one with many lessons and opportunities for future improvement. Total work requirements: 30-min discussion among medical staff.

Case write-up

The medical director emails the case summary to external volunteer clinicians for further input regarding the complications in the hospital course. Total work requirements: $2 \mathrm{~h}$ by medical director.

Team input

External volunteer physicians send several emails discussing pathophysiology and resuscitation protocols. Total work requirements: email conversation including 11 emails in total from five external volunteer physicians, the Bayalpata Hospital's executive director, medical director, and staff physician.

Case conference

During the weekly staff meeting the medical director facilitates a discussion reviewing the case. Three staff members are unfamiliar with the management of pediatric sepsis and severe respiratory distress (Domain of Causal Analysis: Personnel). The nurses explain that the nebuliser was not functioning due to electrical outages and failure of the hospital generator (Domains of Causal Analysis: Equipment, Supply Chains, and Structural). The ambulance driver highlights the lack of sufficient bag valve masks, oxygen tanks, and regulators to share between all hospital departments (Domains of Causal Analysis: Clinical operations and Equipment). Total work requirements: $1 \mathrm{~h}$ M\&M meeting including 16 staff.

Recommendations

The staff and senior management agree that personnel training is needed to review pediatric sepsis and resuscitation protocols. Additional oxygen tanks, regulators, and masks are needed for the ambulance, emergency room, and inpatient wards. Total work requirements: none (part of the case conference described above).

M\&M summary write-up

The medical director summarises the content of the discussion, recommendations, and lessons learnt, and emails the write-up to all external volunteer physicians. This generates several further email exchanges regarding oxygen administration in pediatric resuscitation. Total work requirements: $2 \mathrm{~h}$ by the Bayalpata hospital director of community health.

Recommendation implementation

Two weeks later, physicians conduct a review of clinical protocol and skills. The hospital administrator and procurement staff obtain new oxygen tanks, regulators, and masks from the capital city; however, due to supply chain difficulties, this procurement takes over 2 months. Total work requirements: approximately $10 \mathrm{~h}$ over the course of 2 months.
Pharmacy and medical equipment

An M\&M reviewing a suicide attempt documented lack of antidepressant and antipsychotic medicines in the $\mathrm{BH}$ pharmacy (Domains of Causal Analysis: Clinical operations and Supply chains). After procuring several new medicines, that same patient was placed on outpatient fluoxetine therapy. Six months later, he remains in follow-up and has improved substantially.

\section{DISCUSSION}

\section{Lessons learnt}

Our experience suggests that a modified systemsoriented M\&M programme such as the one described is a simple, feasible strategy for quality improvement in resource-limited settings. At our hospital in rural Nepal, despite challenges with implementation, our staff were able to identify problem areas and steps for improvement in healthcare delivery. In implementing this programme we have identified four key lessons.

\section{Involve both clinical and non-clinical staff}

The majority of M\&Ms worldwide are conducted as conferences primarily for senior-level clinicians. ${ }^{4} 17$ Our experience suggests the involvement of both clinical and non-clinical staff will help to identify broader systemslevel issues to impact patient care.

\section{Structure discussions with a systems-level perspective}

M\&Ms typically focus on medical aspects of cases. Here, we utilised a seven-domain root-cause analysis to better identify systems-level issues and areas for quality improvement. As discussed in other recent literature, ${ }^{4-12}$ this approach helps remove blame from individuals and instead focus on systems, thereby creating a culture of learning more focused on quality improvement.

\section{Foster senior managerial commitment}

Managerial oversight is integral to the success of such a programme. Specifically, oversight is needed to ensure conferences occur consistently, time is allocated in work schedules to facilitate M\&M attendance, all staff are encouraged to participate, and finally that recommendations are pursued after conferences.

\section{Use M\&Ms to guide resource utilisation}

The M\&M has helped $\mathrm{BH}$ staff better target limited resources to critical problem areas (eg, emergency room equipment, staff training). In many settings like ours, demands outstrip resources. M\&Ms offer a mechanism to prioritise competing demands using input from firsthand staff experience.

\section{Limitations}

Limitations to our study include implementation of a small, qualitative study at a single site with external 
volunteer support. While external support has added the benefit of expert medical input and education, several M\&Ms were conducted successfully with no external volunteer input. In our reviews, we found that almost all recommendations resulting in changes to clinical or management protocols came from staff discussions, illustrating the value of the programme even in the absence of external support.

The study is also limited as two lead investigators - the executive director (DS) and medical director (BG) - are the two most senior members of staff, thereby introducing potential bias into the process of eliciting critical feedback from staff about the programme and its implementation.

\section{Next steps}

At $\mathrm{BH}$, we endeavour to soon fund a full-time quality improvement staff member, part of whose responsibilities will include overseeing the consistent and effective implementation of M\&Ms and follow through on all identified problems and recommendations. Additionally, we aim to provide on-site training for our mid-level clinical providers and midwives regarding general quality improvement principles, which will help to fully realise the potential of M\&Ms and further develop broad quality improvement initiatives at $\mathrm{BH}$.

Both at $\mathrm{BH}$ and elsewhere, future research should investigate quantifiable quality outcomes to assess the patient- and operations-level impact of such programmes. This could involve measuring the impact on a suite of plan-do-study-act-driven interventions, as has been done in other studies. ${ }^{9}{ }^{18}$ Additionally, programmes should develop metrics to measure staff engagement in the process of quality improvement.

\section{Conclusion}

We have described an adapted systems-oriented M\&M as a feasible quality improvement tool for resource-limited settings. The M\&M programme at $\mathrm{BH}$ has helped identify and catalyse quality improvement initiatives for healthcare provided in our rural facility.

\footnotetext{
Author affiliations:

${ }^{1}$ Nyaya Health Bayalpata Hospital, Achham, Nepal

${ }^{2}$ Brown University School of Medicine, Providence, Rhode Island, USA

${ }^{3}$ Harvard School of Public Health, Boston, Massachusetts, USA

${ }^{4}$ Department of Medicine, Brigham and Women's Hospital, Boston, Massachusetts, USA

${ }^{5}$ Department of Medicine, Children's Hospital of Boston, Boston, Massachusetts, USA

${ }^{6}$ Division of Infectious Diseases, Massachusetts General Hospital, Boston, Massachusetts, USA

${ }^{7}$ Department of Psychiatry, University of California San Francisco, San

Francisco, California, USA

${ }^{8}$ Institute for Healthcare Improvement, Cambridge, Massachusetts, USA

${ }^{9}$ Department of Medicine, Weill Cornell Medical College, New York, New York, USA

${ }^{10}$ Boston Medical Center, Boston, Massachusetts, USA
}

Acknowledgements The authors would like to graciously acknowledge the contributions of Dr Sanjay Basu for his comments and guidance in this work.

Funding Financial support for the programme was provided by grants to DM from the Frederick Lovejoy Foundation at Children's Hospital Boston and the Brigham and Women's Hospital Center of Expertise on Quality and Safety.

\section{Competing interests None.}

Ethics approval Boston Medical Center in USA; Nepali Health Research Council in Nepal.

Contributors The authors are professionals who work in varying capacities with Nyaya Health, a non-profit group delivering healthcare services in rural Nepal that is innovating methods of open-access and transparency in the field of global health. The authors' contributions are as follows. DM conceived of the study and guided the initial pilot of the programme, and serves as the guarantor of the article. DS oversaw the programme locally, adapted the initial pilot into a formal programme, wrote the initial draft, and analysed the data. RS analysed the data and contributed to the drafting of the manuscript. BG, $A B, R S$ and $M G$ served as clinicians and managers on the programme and participated in revision of its aims and methods. BA, RR, JA, GK, KM, and DM provided feedback on the operation of the programme and revised the manuscript. All authors read and approved the final manuscript.

Provenance and peer review Not commissioned; externally peer reviewed.

Data sharing statement The authors commit to sharing all data from the included research. Data can be requested directly from the authors, or accessed directly on the open-source wiki of Nyaya Health (parent organization to Bayalpata Hospital, the site of research) at http://wiki.nyayahealth.org.

\section{REFERENCES}

1. Russell E, Bruce J, Krukowski Z. Systematic review of the quality of surgical mortality monitoring. Br J Surg 2003;90:527-32.

2. Carter B, Guthrie S. Utility of morbidity and mortality conference in end-of-life education in the neonatal intensive care unit. $J$ Palliat Med 2007;10:375-80.

3. Friedman JN, Pinard MS, Laxer RM. The morbidity and mortality conference in university-affiliated pediatric departments in Canada. J Pediatr 2005;146:1-2.

4. Gore DC. National survey of surgical morbidity and mortality conferences. Am J Surg 2006;191:708-14.

5. Antonacci A, Lam S, Lavarias V, et al. A report card system using error profile analysis and concurrent morbidity and mortality review: surgical outcome analysis, part II. J Surg Res 2009;153:95-104.

6. Supratikto $G$, Wirth M, Achadi $E$, et al. A district-based audit of the causes and circumstances of maternal deaths in South Kalimantan, Indonesia. Bull World Health Organ 2002;80:228-34.

7. Almerie $\mathrm{Y}$, Almerie $\mathrm{M}$, Matar $\mathrm{H}$, et al. Obstetric near-miss and maternal mortality in maternity university hospital, Damascus, Syria: a retrospective study. BMC Pregnancy Childbirth 2010;10:65.

8. Mancey-Jones M, Brugha R. Using perinatal audit to promote change: a review. Health Policy Plan 1997;12:183-92.

9. Szostek JH, Wieland ML, Loertscher LL, et al. A systems approach to morbidity and mortality conference. Am J Med 2010;123:663-8.

10. McDonnell C, Laxer RM, Roy WL. Redesigning a morbidity and mortality program in a university-affiliated pediatric anesthesia department. Jt Comm J Qual Patient Saf 2010;36:117-25.

11. Orlander JD, Barber TW, Fincke BG. The morbidity and mortality conference: the delicate nature of learning from error. Acad Med 2002;77:1001-6.

12. Szekendi MK, Barnard C, Creamer J, et al. Using patient safety morbidity and mortality conferences to promote transparency and a culture of safety. Jt Comm J Qual Patient Saf 2010;36:3-9.

13. Schwartz H. Nutritional Anthropometric Survey, Children from 6 to 59 months, Achham District, Nepal. Action contre la faim. 2008.

14. District Health Office of Achham, Nepal. Annual Report 2066-2067 (2009-2010). Nepali Ministry of Health and Population and Kathmandu Publishing House. 1st ed. 2010.

15. Ishikawa K, Loftus JH. Introduction to Quality Control. Tokyo, 3A Corporation, 3rd ed. 1990.

16. Maru D. Nyaya Health's Mortality Review Program. 2009. http://blog. nyayahealth.org/2009/10/29/mortalityreview/ (accessed 12 Sep 2011)

17. Orlander JD, Fincke BG. Morbidity and mortality conference: a survey of academic internal medicine departments. J Gen Int Med 2003;18:656-8.

18. Kotagal $\mathrm{M}$, Lee $\mathrm{P}$, Habiyakare $\mathrm{C}$, et al. Improving quality in resource poor settings: observational study from rural Rwanda. BMJ 2009;339: b3488. 